\title{
Diferenciais no Comportamento Reprodutivo das Mulheres Brasileiras: Uma Análise a partir dos Grupos Ocupacionais
}

Cláudio Santiago Dias Júnior

\section{INTRODUÇÃO}

S egundo dados da Pesquisa Nacional por Amostra de Domicílios $\mathcal{O}$ (PNAD), em 2007 o Brasil apresentava uma taxa de fecundidade total (TFT) de 1,95 filho por mulher. Não obstante, diversas pesquisas têm identificado a existência de subgrupos populacionais com altas taxas de fecundidade total, chegando em alguns casos, a seis filhos por mulher. Essas pesquisas quase sempre analisam os diferenciais de fecundidade a partir de escolaridade, renda, região geográfica e raça (Berquó e Cavenaghi, 2005; Horta, Carvalho e Nogueira, 2005; Alves, 2004; Fundação Seade, 2004; IBGE, 2000; Lam e Duryea, 1999), e deixam de lado aspectos relacionados ao trabalho e à ocupação da mulher (Dias Júnior, 2007). Nesse sentido, o objetivo, neste artigo, é examinar como o comportamento reprodutivo, representado pelo número de filhos, pela idade ao ter os filhos e pelo intervalo intergenésico, pode estar associado à ocupação da mulher.

Este estudo parte da hipótese de que determinados tipos de ocupação estão associados a diferentes estratégias utilizadas pelas mulheres em relação à fecundidade. Espera-se que, entre as mulheres mais qualificadas, que normalmente estão inseridas na parcela mais competitiva do mercado de trabalho (cuja formação acadêmica é um pré-requisito, e o constante aperfeiçoamento profissional, uma exigência), o custo de

DADOS - Revista de Ciências Sociais, Rio de Janeiro, vol. 53, nº 1, 2010, pp. 233 a 265. 
oportunidade de ter filhos seja maior, e a incompatibilidade entre o trabalho e a família, mais acentuada. Nessas situações, pode-se esperar um adiamento e uma limitação da fecundidade (Hewllet, 2002; Brewster e Rindfuss, 2000; Kalwij, 2000; Ellisgsaeter e Rosen, 1996; Blau e Robins, 1989; Becker, 1981).

Foram introduzidos, neste artigo, dois aspectos importantes para o debate atual da fecundidade no Brasil. O primeiro foi a estratificação do grupo ocupacional da mulher em oito categorias. Acredita-se que, ao utilizar essa categorização, a tradicional divisão entre ocupada/não ocupada é minimizada, proporcionando ao estudo da fecundidade uma análise mais refinada da relação entre o comportamento reprodutivo e a ocupação. Como bem lembra Alves (2004), é a qualidade do emprego que faz com que a mulher tenha um maior controle sobre suas decisões reprodutivas, e não apenas o fato de trabalhar.

Além disso, deve-se ressaltar que a categorização dos grupos ocupacionais foi pautada pela preocupação em minimizar o papel da educação (que normalmente é o marco referencial utilizado na classificação ocupacional) e valorizar os aspectos próprios da ocupação, como as tarefas demandadas e a competência exigida. Para realizar essa tarefa, foi utilizada a categorização ocupacional da nova Classificação Brasileira de Ocupações (CBO), que traz em sua essência toda essa preocupação ${ }^{1}$.

O segundo aspecto foi a introdução do tempo ${ }^{2}$ para produzir algumas medidas de fecundidade. De acordo com Ryder (1969), apesar da importância do tempo, o que tem sido observado é que as análises da fecundidade são centradas nas questões referentes à parturição, deixando de lado aspectos como a idade ao ter os filhos e o intervalo intergenésico. Para esse autor, essa tendência se justificaria pelos seguintes motivos: 1 ) as maiores transformações na fecundidade têm sido observadas no volume de nascimentos; 2) quase todas as medidas de fecundidade são medidas de período, o que inibe o uso de parâmetros de coorte, como o tempo de ocorrência do evento; 3) a influência da mudança no tempo sobre a quantidade de filhos é bastante sutil, quase sempre imperceptível.

Buscando cobrir essa lacuna, foram utilizadas informações sobre a história de nascimentos da amostra do Censo Demográfico 2000 do IBGE (Instituto Brasileiro de Geografia e Estatística). A partir dessas informações, é possível obter uma perspectiva de coorte, permitindo uma 
análise mais profícua do processo reprodutivo (Schoen, 2006; Bongaarts e Feeney, 1998; Newell, 1988; Berquó, 1980; Sauvy, 1979; Ryder, 1969).

\section{POSSIBILIDADES TEÓRICAS PARA A INTERPRETAÇÃO DA RELAÇÃO ENTRE O COMPORTAMENTO REPRODUTIVO E O GRUPO OCUPACIONAL DA MULHER}

Com evidências cada vez mais fortes da relação entre o declínio da fecundidade e o aumento da participação da mulher no mercado de trabalho, é cada vez maior o interesse dos pesquisadores em entender esse fenômeno. Nesse sentido, tanto a sociologia quanto a economia vêm construindo um importante arcabouço teórico-metodológico para a compreensão da relação entre essas duas variáveis, colaborando diretamente para os avanços dos estudos demográficos nessa área. $\mathrm{Na}$ perspectiva sociológica, a análise se baseia na hipótese da incompatibilidade entre o papel de mãe/dona de casa com o de mulher trabalhadora. Já na perspectiva econômica, a análise está baseada nos custos de oportunidade de ter um filho.

Tanto a abordagem sociológica quanto a econômica colaboram para o debate em torno da inserção da mulher no mercado de trabalho e os possíveis impactos desse fenômeno sobre o comportamento reprodutivo. Apesar de constituírem dois marcos conceituais diferentes, essas duas possibilidades de análise não são necessariamente antagônicas, uma vez que a incompatibilidade de papéis aumenta com o crescente custo de oportunidade de ter filhos (Engelhardt, Kögel e Prskawetz, 2004).

\section{Incompatibilidade de Papéis}

A necessidade de desempenhar simultaneamente vários papéis sociais pode gerar certo grau de incompatibilidade entre eles. Um dos exemplos mais comuns na literatura é o conflito enfrentado pelas mulheres que tentam conciliar o papel de mãe/dona de casa com o de trabalhadora. Para muitos autores, esse conflito é a base para entender como a inserção da mulher no mercado de trabalho se associa à fecundidade (Blau, Ferber e Winkler, 1998; Jones, 1981).

Segundo pesquisas realizadas pelas Nações Unidas (1985), nas sociedades nas quais existe algum nível de incompatibilidade entre as atividades domésticas e as profissionais, as mulheres que trabalham têm, 
em média, menos filhos, quando comparadas com as mulheres que não trabalham (Blau e Robins, 1989). Nos países ocidentais, por exemplo, quanto maior a participação da mulher no mercado de trabalho, menor a taxa de fecundidade (Pazello, 2004; Kögel, 2004; Lloyd, 1990).

Outro aspecto importante a ser destacado quando se estuda a relação entre a fecundidade e a participação da mulher no mercado de trabalho se refere à ocupação. Hakim (1992) e England (1991) demonstram que há uma relação da fecundidade com as características da ocupação da mulher. Para essas autoras, as ocupações que são mais flexíveis tanto em relação aos horários quanto em relação à facilidade de entrar e sair do mercado de trabalho - são preferidas pelas mulheres. Essa preferência ocorre em virtude da necessidade de conciliação entre os afazeres domésticos e maternos com a vida profissional. Segundo Hewllet (2002) e Villarreal (1996), em ocupações de alto status social (normalmente ocupações de nível superior com possibilidade de carreira), é frequente a incompatibilidade entre o trabalho e os cuidados com os filhos. Para as mulheres nessas ocupações, a maternidade se torna um grande empecilho para o desenvolvimento profissional, uma vez que a saída do mercado de trabalho para ter um filho pode acarretar uma desvantagem futura para a carreira. Por outro lado, nas ocupações sem prestígio social, existe uma possibilidade maior de compatibilidade entre o trabalho e os cuidados com os filhos, visto que não há grandes expectativas em relação à carreira profissional. Essa falta de perspectiva profissional facilita as entradas e saídas das mulheres no mercado de trabalho, em função da maternidade, sem grandes prejuízos materiais.

De acordo com Favaro (2004) e Presser (1989), a presença de mecanismos institucionais voltados para os cuidados com as crianças pode amenizar, ou mesmo neutralizar, a incompatibilidade entre os papéis de mãe/dona de casa e o de trabalhadora. Esse fenômeno tem sido observado sobretudo nos países escandinavos e na Alemanha, onde, após grandes investimentos em childcare, detectou-se um aumento da participação da mulher no mercado de trabalho, ao mesmo tempo que se observou um aumento nas taxas de fecundidade (Brewster e Rindfuss, 2000; Ondrich e Spiess, 1998; Ellingsaeter e Ronsen, 1996). Entretanto, ainda é muito cedo para aceitar a ideia de que a incompatibilidade entre os papéis de mãe e trabalhadora esteja com os dias contados nas sociedades ocidentais. 


\section{Custos de Oportunidade}

Em praticamente todas as culturas, segundo a teoria microeconômica, as obrigações domésticas são tarefas exclusivas das mulheres. Tendo essas obrigações a priori, as mulheres, na maioria das vezes, são levadas a escolher ocupações que permitam a conciliação entre a casa e o trabalho. Ao buscar conciliar a tarefa doméstica e a profissional, elas acabam se concentrando em ocupações de tempo parcial e/ ou flexível, cujo retorno financeiro é baixo e a construção de carreiras é muito difícil. Nesse ambiente, o custo de oportunidade de ter um filho é baixo, o que pode incentivar a fecundidade (Degraff e Anker, 2004; Hirata e Kergoat, 2003; Anker, 1997; England, 1991; Becker, 1981).

Segundo o modelo da compensação, uma das abordagens da teoria microeconômica, as mulheres mostram-se dispostas a abrir mão de uma ocupação que possa proporcionar maiores ganhos e carreira para ingressar em ocupações que possibilitem uma segurança maior tanto em relação ao trabalho em si quanto em relação à sua família e a seus filhos. Ou seja, as mulheres buscam ocupações que permitam a compatibilidade entre a casa, a maternidade e o trabalho (Degraff e Anker, 2004).

Esse modelo pode tornar-se frágil se forem considerados os ganhos educacionais observados entre as mulheres nos últimos anos. Com o aumento da escolaridade delas, muitas estão ingressando no mercado de trabalho em ocupações de primeira linha, disputando com os homens as melhores colocações. O ganho educacional, que resulta em melhores empregos e salários, aumenta o custo de oportunidade de ter filhos. Ou seja, é de se esperar que entre as mulheres mais escolarizadas, potencialmente alocadas em ocupações promissoras, haja um controle maior da fecundidade (Brewster e Rindfuss, 2000; Anker, 1997).

Além do aumento da escolaridade, as transformações nos padrões de casamento (o aumento da idade média da mulher ao se casar e o crescimento do percentual de coabitação) e de reprodução (a postergação da maternidade) produziram uma diminuição dos afazeres domésticos. Com isso, as mulheres passaram a ter menos obrigações com o lar e mais tempo para se especializar profissionalmente e adquirir mais experiência no mercado de trabalho (McDonald, 2001; Anker, 1997; England, 1991). 
Diante desses argumentos, pode-se dizer que, entre as mulheres com um maior capital humano, o custo de oportunidade de ter um filho é maior. É de se esperar que esse grupo postergue a maternidade, uma vez que investe muito no mercado de trabalho (Becker, 1981). Por outro lado, para as mulheres com menor capital humano, pode-se dizer que o custo de oportunidade de ter um filho não é tão expressivo a ponto de restringir consideravelmente a fecundidade.

Sylvia Hewllet (2002) corrobora essa visão. Em um estudo qualitativo realizado nos Estados Unidos, essa autora analisou as mulheres em profissões de alto prestígio social (basicamente executivas de grandes empresas). Segundo esse estudo, o caminho trilhado por essas mulheres até a chegada ao topo da pirâmide ocupacional foi árduo, exigindo posturas mais "masculinizadas" para que sobrevivessem à forte competição no mercado de trabalho. Nesse ambiente hostil, observou-se que as demandas reprodutivas foram inibidas, contribuindo para a postergação da maternidade. Em alguns casos, segundo Hewllet, a postergação é tão extrema que se torna praticamente impossível ter filhos, em virtude das limitações biológicas do organismo feminino. Ao contrário, os homens nas mesmas posições ocupacionais possuíam, em média, três filhos. Em outro estudo, Stolzenberg e Waite (1977) observam que o efeito negativo da participação da mulher no mercado de trabalho sobre a fecundidade é mais forte em relação ao primeiro filho, sobretudo entre as mulheres em ocupações mais privilegiadas. Já para Hoem e Hoem (1989), o impacto negativo ocorre em todas as ordens de nascimento. Esses autores observaram que, para as mulheres que participam do mercado de trabalho, a probabilidade de terem muitos filhos é menor quando comparadas com as mulheres que não trabalham.

\section{BANCO DE DADOS}

Para este estudo, foram utilizados os dados do arquivo de pessoas da amostra do Censo Demográfico 2000. Esse arquivo é representativo para o Brasil e conta com informações de 20.274.412 pessoas (sem peso). Desse universo, foram selecionadas as mulheres do grupo etário de 30 a 34 anos, classificadas, dentro da família, como pessoa responsável ou cônjuge. Essas escolhas foram pautadas por três motivos.

O primeiro deles era a necessidade de alocar as informações da idade dos filhos nascidos vivos junto das respectivas mães para construir a história de nascimentos. De acordo com a estrutura do Censo Demo- 
gráfico 2000, no caso das mulheres classificadas como responsáveis pela família ou como cônjuges, é possível a alocação das informações dos filhos nascidos vivos; para as demais categorias, a possibilidade de alocação dessas informações é quase nula.

O segundo motivo é a necessidade de trabalhar com mulheres já estabilizadas profissionalmente e com a fecundidade praticamente encerrada. Para Pastore e Silva (2000), o corte etário ideal nos estudos sobre trabalho e ocupação é 30 anos. De acordo com esses autores, nessa idade o indivíduo praticamente encerrou seu processo de formação profissional (principalmente via educação formal) e já se encontra estabilizado na ocupação. Ou seja, as possibilidades de uma grande mudança no status ocupacional dos indivíduos, a partir dos 30 anos, são remotas. A mobilidade observada ocorre dentro da própria ocupação. O corte aos 30 anos também contempla a questão da fecundidade, uma vez que essa é uma idade em que o ciclo reprodutivo das mulheres já está próximo de se tornar completo. De acordo com Miranda-Ribeiro (2004), em 2000, a idade média da mulher brasileira ao ter o quarto filho era 29,3 anos. Como o total de mulheres com parturição acima de dois filhos está declinando rapidamente no Brasil, é razoável supor que o limite inferior da amostra aos 30 anos de idade garante um grande número de mulheres com a parturição praticamente encerrada.

O terceiro motivo é a necessidade de reduzir a proporção de mulheres com informações incompletas sobre os filhos. Nesse sentido, com o corte superior aos 34 anos, tem-se um percentual de mulheres com informações incompletas sobre os filhos bastante reduzido em relação a grupos etários mais velhos.

Após essas ponderações, foram retiradas de nossa amostra todas as mulheres com filhos gêmeos, mulheres com um número de filhos nascidos vivos menor do que o número de filhos presentes na família, mulheres cuja idade ao ter o primeiro filho não fosse 15 anos ou mais ${ }^{3} \mathrm{e}$ mulheres classificadas como amarelas e indígenas no quesito cor.

Ao final, o banco de dados passou a contar com 635.788 mulheres de 30 a 34 anos, classificadas como responsáveis pela família ou como cônjuges (sem peso). Com a expansão da amostra, esse banco de dados chegou a 5.431 .732 casos. Desse total, $82,2 \%$ das mulheres não possuem filhos ou possuem todas as informações das idades dos filhos nascidos vivos (mulheres com dados completos); e 17,8\% apresentam alguma 
perda de informação das idades dos filhos nascidos vivos (mulheres com dados incompletos).

A presença de mulheres com dados incompletos no banco de dados suscitou importantes questões sobre a manutenção ou não desses casos nas análises. A saída mais simples para essa situação seria restringir as análises ao grupo de indivíduos com todas as informações, utilizando o list-wise deletion (Chen e Astebro, 2003). Nesse sentido, assume-se que os casos descartados por falta de informações têm as mesmas características dos casos completos. No entanto, isso só ocorre se os dados descartados representarem uma subamostra aleatória da amostra original. Outro método utilizado para solucionar a ausência de informações é a substituição dos missing pela média dos dados válidos da variável em questão. O grande problema desse método é que todos os missing recebem o mesmo valor médio, o que faz com que a variância se reduza artificialmente. Outro instrumental para solucionar a presença de missing em um banco de dados é a imputação via regressão. Com esse instrumental, os dados ausentes são produzidos a partir dos valores encontrados em outras variáveis. Um aspecto a ser ressaltado é que os valores produzidos a partir de um modelo de regressão não têm o objetivo de se tornar o valor real, mas sim de garantir a variabilidade da população, preservando as correlações com as outras variáveis (Schafer, 1999).

Após a comparação de mulheres com dados completos com as mulheres com dados incompletos, foram identificadas importantes diferenças socioeconômicas entre elas ${ }^{4,5}$. Essas diferenças inviabilizam tanto a utilização do list-wise deletion quanto a substituição dos missing pela média das informações encontradas. A opção por um desses dois procedimentos produziria uma amostra fortemente viesada, sendo que a utilização do procedimento list-wise deletion geraria uma amostra com apenas 83\% das mulheres de 30 a 34 anos, o que impossibilitaria a generalização dos resultados. Diante desses fatos, a melhor solução foi imputar as informações dos filhos ausentes a partir de um modelo de regressão e assim garantir que a amostra fosse realmente representativa do universo.

As mulheres foram separadas em subgrupos, segundo a parturição (0 a 5 filhos). Para cada subgrupo, excetuando as mulheres sem filhos, foi construída uma equação de regressão. Para as mulheres com um filho, foi construída uma equação para estimar a idade ao ter o primeiro fi- 
lho; para as mulheres com dois filhos, foram construídas duas equações para estimar a idade ao ter o primeiro e o segundo filho; e assim sucessivamente, até o quinto filho. Esse procedimento foi avaliado como o mais adequado por considerar a parturição da mulher nos cálculos das idades ao terem os filhos e por minimizar as possíveis reduções da variância total ao reagruparmos todas as informações.

No modelo de regressão, a variável dependente é a idade ao ter o filho, e as variáveis independentes são escolaridade, cor/raça e situação do domicílio. A variável escolaridade foi categorizada em analfabeta, 1 a 3 anos de estudo, 4 a 7 anos de estudo, 8 a 10 anos de estudo e 11 anos e mais de estudo; a variável cor / raça, em branca e negra; e a variável situação do domicílio, entre urbana e rural. A escolha dessas variáveis foi baseada na literatura demográfica, que aponta escolaridade, cor/raça e situação do domicílio como fatores preponderantes no regime reprodutivo da mulher brasileira (Fundação Seade, 2004; IBGE, 2000; Lam e Duryea, 1999; Wood e Carvalho, 1994).

Após a estimação de todas as idades das mulheres ao terem os filhos, foram comparados os valores observados no Censo Demográfico 2000 com os valores produzidos pelas equações de regressão para atestar a validade do procedimento utilizado (Tabela 1 ).

\section{Tabela 1}

Idade média das mulheres de 30 a 34 anos ao terem seus filhos, segundo a ordem de nascimento

\begin{tabular}{l|c|c|c|c|c}
\hline Filho & A & B & C & D & E \\
\hline 1 & 22,51 & 22,51 & 20,45 & 22,12 & 22,12 \\
2 & 24,90 & 24,87 & 22,91 & 24,42 & 24,44 \\
3 & 26,09 & 25,96 & 24,86 & 25,57 & 25,66 \\
4 & 26,96 & 26,64 & 26,23 & 26,44 & 26,61 \\
5 & 27,96 & 27,95 & 27,93 & 27,94 & 27,94 \\
\hline
\end{tabular}

Fonte: IBGE, Censo Demográfico 2000.

A - Idade observada no Censo Demográfico 2000 (mulheres com informação completa).

B - Idade estimada (mulheres com informação completa).

C - Idade estimada (mulheres com informação incompleta).

D - Idade estimada (mulheres com informação completa e incompleta).

E - Idade observada no Censo Demográfico 2000 (mulheres com informação completa) mais idade estimada (mulheres com informação incompleta).

Comparando as informações das colunas A e B, percebe-se que os valores estimados para as mulheres com informações completas pelo modelo de regressão (B) estão bem próximos dos valores observados diretamente do Censo Demográfico (A). Já a coluna C mostra os valores es- 
timados para as mulheres com informações incompletas. Fica claro que as médias delas são inferiores às das mulheres com informações completas. Essa diferença era esperada, visto que as condições socioeconômicas dessas mulheres com informações incompletas são piores, o que pode levar a uma parturição maior e, por consequência, a uma entrada na maternidade mais cedo, fazendo com que as idades médias sejam menores.

Validado o método de imputação e mantidas as mulheres com informações imputadas, o banco de dados passou a contar com mais de 5 milhões de casos, sendo que cerca de $83 \%$ das informações sobre a idade ao ter os filhos foram retiradas diretamente do Censo Demográfico e o restante foi gerado a partir dos modelos de regressão.

\section{MODELO ANALÍTICO}

O modelo analítico apresenta o comportamento reprodutivo da amostra, a partir do grupo ocupacional da mulher, que foi desenvolvido com base na nova Classificação Brasileira de Ocupações (CBO).

A nova $\mathrm{CBO}$ descreve e ordena as ocupações dentro de uma estrutura hierarquizada, segundo características ocupacionais que dizem respeito à natureza da força de trabalho (funções, tarefas e obrigações que tipificam a ocupação) e ao conteúdo do trabalho (conjunto de conhecimentos, habilidades, atributos pessoais e outros requisitos exigidos para o exercício da ocupação). É importante destacar que a nova CBO considerou uma compreensão mais atualizada de "competência", cujo nível é pontuado mais fortemente pela complexidade das atividades exercidas do que pelo nível de escolaridade ${ }^{6}$. Ao centrar a classificação das ocupações na competência, em detrimento da educação, a nova $\mathrm{CBO}$ consegue produzir uma categorização mais pura de ocupação. No entanto, essa nova metodologia não faz com que a educação esteja totalmente afastada do processo construtivo das categorias ocupacionais, o que, aliás, seria impossível. A educação é um fator fundamental na definição de uma ocupação, mas, considerando a maneira como essa questão foi trabalhada pela nova $\mathrm{CBO}$, a importância dela é diminuída em favor da natureza e do conteúdo do trabalho realizado em cada ocupação. A correlação entre ocupação e educação fica, portanto, menor, diminuindo a possibilidade de confundimento entre o comportamento reprodutivo e essas duas variáveis. 
Essa nova classificação é composta de 10 grandes grupos ocupacionais; 47 subgrupos principais; 192 subgrupos; 596 grupos de base ou famílias ocupacionais, em que se agrupam 2.422 ocupações; e 7.258 títulos sinônimos.

Diante das inúmeras possibilidades apresentadas pela nova $\mathrm{CBO}$, a variável ocupação foi construída a partir dos grandes grupos que formam o nível mais agregado da classificação. Essa escolha refletiu a busca por um modelo parcimonioso, que representasse a essência das diferenças ocupacionais entre as mulheres.

O primeiro passo foi criar o grupo de empregadas domésticas. Esse grupo foi criado dado o peso dessa ocupação para o grupo de mulheres trabalhadoras. O segundo passo foi agrupar em uma mesma categoria as profissionais de nível técnico e administrativo (categoria técnico-administrativa) e as profissionais de produção e manutenção (categoria produção/manutenção). Os demais grupos ocupacionais foram mantidos de acordo com a nova CBO. Além disso, foi incluída a categoria não ocupada. Dessa forma, a variável grupo ocupacional ficou assim categorizada ${ }^{7}$ :

- direção e gerência;

- nível superior;

- técnico-administrativo;

- serviços;

- rural;

- produção/manutenção;

- trabalhadoras domésticas;

- não ocupadas.

As medidas do comportamento reprodutivo utilizadas neste trabalho foram a parturição, a TFT (taxa de fecundidade total), a idade média ao ter os filhos e o espaçamento médio entre os nascimentos.

A medida de parturição foi retirada diretamente do Censo Demográfico 2000. A TFT foi calculada a partir da Parity Progression Ratio (PPR). A PPR é basicamente a probabilidade de se ter um filho de ordem $\mathrm{x}+1$ desde que se tenha um filho de ordem x (Newell, 1988). Normalmente, a PPR é utilizada em coortes que já encerraram a vida reprodutiva, isto é, coortes com 50 anos e mais de idade. Neste artigo, essa metodologia foi utilizada para o grupo de mulheres de 30 a 34 anos, pois é provável que grande parte dessas mulheres tenha encerrado sua vida reproduti- 
va, o que permite a aplicabilidade dessa técnica aos dados (embora as PPRs e, portanto, as TFTs possam estar sendo subestimadas pela parturição ainda incompleta de parte dessas mulheres).

Para calcular a TFT a partir da PPR, foram utilizadas as seguintes informações:

$W_{x}=$ número de mulheres com parturição $x($ até parturição $=n)$;

$B_{x}=$ número de nascimentos de parturição $x$.

A partir dessas informações, aplicou-se a fórmula (1) para estimar os valores das TFTs para cada grupo ocupacional:

$\operatorname{TFT}=\frac{B}{W}=\frac{\sum_{x-1}^{n} B_{x}}{\sum_{x=0}^{n} W_{x}}=\sum_{x-1}^{n} P P R_{(0, x)}$

Aidade média ao ter os filhos, em cada uma das parturições, segundo o grupo ocupacional, foi calculada a partir da fórmula (2):

$I_{x}=I_{m 2000}-I_{f x 2000}$

Em que:

I é a idade da mãe ao ter o filho;

$x$ é a ordem de parturição;

$I_{m 2000}$ é a idade da mãe em 2000;

$I_{f x} 2000$ é a idade do filho em 2000 (segundo a ordem de parturição).

Essa fórmula foi aplicada para cada uma das ordens de nascimento. A partir desses resultados, foi calculada a idade média das mulheres ao terem os filhos (de ordem 1 a 5) para cada um dos grupos ocupacionais.

O espaçamento entre os nascimentos, ou o intervalo intergenésico, pode ser definido como o tempo entre os sucessivos nascimentos (de nascidos vivos). Os abortos e os nascidos mortos não são considerados nesse cálculo. Cada intervalo começa com um período de amenorreia pós-parto (esse período pode ser ampliado se a lactação for prolongada) até o retorno do ciclo menstrual, que, por sua vez, pode ser seguido por um período de uso de contracepção. Em seguida, pode haver um 
período de espera entre o fim da adoção da contracepção e a concepção. Finalmente, ocorre a gravidez, que normalmente dura nove meses. O intervalo, então, termina com o nascimento da criança (Preston, Heuveline e Guillot, 2001; Newell, 1988). É importante destacar que o intervalo mínimo possível entre os nascimentos é de dez meses (excetuando casos de partos prematuros), mas ele é, normalmente, maior do que isso, chegando, em alguns casos, a vinte anos.

É evidente que esses cálculos podem ser muito mais complicados, sobretudo se o objetivo do estudo for a efetividade de métodos contraceptivos (id., ibid.; id., ibid.). Como este estudo não se ocupa dessas questões, a medida de intervalo de nascimento é mais simples. O intervalo médio entre os nascimentos foi baseado no cálculo realizado para a construção da história de nascimentos nas vidas dessas mulheres. $\mathrm{O}$ primeiro intervalo, que teoricamente não é considerado um intervalo intergenésico, foi calculado pela fórmula (3):

$T_{1}=I_{1}-15$

Em que:

$T_{1}$ é o intervalo até o primeiro nascimento;

$I_{1}$ é a idade da mulher ao ter o primeiro filho;

15 é a idade de início do período reprodutivo.

Os demais intervalos foram calculados pela fórmula (4):

$T=I_{x+1}-I_{x}$

Em que:

T é o intervalo intergenésico;

$I_{x+1}$ é a idade da mãe ao ter o filho $\mathrm{x}+1$;

$I_{x}$ é a idade da mãe ao ter o filho $\mathrm{x}$.

A partir dessas informações, foi calculado o intervalo intergenésico médio em cada um dos grupos ocupacionais.

\section{UMA NOTA METODOLÓGICA SOBRE A RELAÇÃO ENTRE COMPORTAMENTO REPRODUTIVO E OCUPAÇÃO}

As escolhas feitas durante a vida de uma mulher, em conjunto com as condições materiais e socioculturais colocadas à sua disposição, respondem, em grande parte, pelo resultado reprodutivo e ocupacional 
obtido por ela. Nesse contexto, o estabelecimento de uma direção na relação causal entre esses dois fenômenos não é trivial, principalmente porque é muito difícil a obtenção das datas de ocorrência dos eventos relativos à parturição e à carreira profissional de um mesmo indivíduo. Sem essas informações, não é possível dizer se foi o "resultado ocupacional" que causou o "resultado da fecundidade" ou vice-versa. Dessa forma, os resultados de um modelo de determinação baseado em uma pesquisa cross-section podem estar inteiramente viesados, visto que as características identificadas no momento da coleta dos dados podem ter sido determinadas por planejamentos passados e podem estar sendo moldadas por expectativas futuras. Neste estudo específico, a história reprodutiva das mulheres pode não ter uma relação com sua ocupação atual, observada no momento da pesquisa. Contudo, deve-se salientar que a ocupação presente também é resultado de uma trajetória que foi construída em cima de possibilidades e desejos individuais. Existe a possibilidade real de diálogo entre esses dois fenômenos sociais, com ambos influenciando-se mutuamente.

Segundo Cramer (1980), é impossível observar uma relação temporal entre a fecundidade acumulada (parturição total) e as variações da participação feminina no mercado de trabalho. Assumindo que essas variáveis são endógenas, o modelo estático pode não ser satisfatório, já que ignora a forma como tais variáveis foram planejadas. Além disso, Cramer nos mostra que tanto o planejamento sobre a fecundidade quanto a trajetória futura da mulher no mercado de trabalho podem afetar os resultados de duas maneiras diferentes. Em primeiro lugar, podem afetar diretamente a relação causal observada a partir dos dados correntes. Por exemplo, o impacto do nascimento de um filho na participação da mulher no mercado de trabalho pode ser diferente se essa criança for planejada ou se nascer "acidentalmente". Em segundo, mesmo que o planejamento das variáveis não afete a relação causal corrente (ou presente) por meio da sequência das decisões tomadas, ele deve provavelmente afetar o número (ou frequências) dessas sequências. Um exemplo desse efeito dado por Cramer é que o planejamento da história reprodutiva pode não alterar o impacto de um nascimento na carreira profissional da mulher, mas deve ajudar a determinar o número total de filhos tidos ou que ainda nascerão.

O estabelecimento da causalidade exige um ordenamento temporal e certa contiguidade entre as variáveis. Esse estabelecimento pode ser dificultado pelo fato de que os indivíduos podem pensar prospectiva- 
mente, ou seja, podem planejar seus objetivos e traçar suas estratégias muito tempo antes da ocorrência do evento. De maneira geral, pode haver um descompasso temporal entre as estratégias utilizadas e a efetivação do evento.

Para Cramer, um dos principais motivos da dificuldade de se estabelecer uma relação causal entre a fecundidade e a participação da mulher no mercado de trabalho é a qualidade e a especificação das variáveis utilizadas nesses tipos de estudo. De acordo com esse autor, as informações sobre a fecundidade e o trabalho, incluindo as preferências temporais, precisam ser mais bem coletadas e analisadas. A ideia seria imprimir ao modelo uma dinâmica só conseguida com dados longitudinais e com isso ajudar a resolver as questões de causalidade ${ }^{8}$. Apesar disso, Cramer também afirma que, como nos estudos sobre a fecundidade e a participação da mulher no mercado de trabalho não existe um consenso em relação à direção causal, pode-se dizer que ambas as direções podem ser consideradas plausíveis.

Para Villarreal (1996), a dificuldade de se estabelecer uma direção causal entre a fecundidade e a participação da mulher no mercado de trabalho ocorre em virtude da simultaneidade das escolhas em relação à fecundidade desejada e à participação, ou não, no mercado de trabalho. A simultaneidade ofusca a relação observada, impedindo o estabelecimento da causalidade.

Uma maneira eficaz de tentar resolver a questão da simultaneidade seria a utilização do experimento natural, que insere no modelo alguma variável aleatória (Pazello, 2004; Verona, 2004). Outra forma seria a utilização de variáveis instrumentais ${ }^{9}$ (Pazello, 2004) ou o uso de equações simultâneas (Villarreal, 1996).

Segundo Villarreal, uma alternativa para resolver a questão da direção causal nesses tipos de estudo seria a utilização de um modelo dinâmico, baseado em dados longitudinais (seguindo o mesmo respondente por meio de sua vida reprodutiva e produtiva), em contraposição a um modelo estático. Os grandes obstáculos que, em muitos casos, inviabilizam o uso dessa alternativa são o custo e o tempo demandados para a geração de informações relevantes.

Monica Fong (1976) apresenta algumas considerações metodológicas com o objetivo de ajudar a esclarecer a relação causal entre a fecundidade e a participação feminina no mercado de trabalho. Essa autora 
afirma que é importante incluir na análise medidas correntes de fecundidade ao se utilizar medidas recentes sobre o mercado de trabalho feminino. Segundo ela, uma alternativa para lidar com medidas correntes de fecundidade seria a utilização de dados de filhos com até 5 anos de idade ou a idade do último filho tido. Usando tais informações, seria possível captar uma medida mais recente dos "conflitos" entre a demanda por trabalho e filhos. Fong exemplifica dizendo que uma mãe com dois filhos nascidos há doze e nove anos experimenta diferentes obstáculos no mercado de trabalho quando comparada com uma mãe com dois filhos nascidos há três e dois anos, apesar de a parturição dessas mães ser a mesma.

Tendo a percepção desses problemas metodológicos, fica evidente a importância da escolha das variáveis e dos procedimentos utilizados. A maioria das medidas de fecundidade e de participação na força de trabalho não permite associar esses dois itens; normalmente utilizam dados correntes (variável trabalho/ocupação) para serem correlacionados com aspectos ligados à história de vida (fecundidade/parturição). Tais procedimentos podem resultar em relações espúrias entre $o$ comportamento reprodutivo e o trabalho, dificultando a compreensão do comportamento demográfico da população.

Como não existe uma pesquisa longitudinal no Brasil sobre o comportamento reprodutivo e a participação das mulheres no mercado de trabalho, foi necessário adequar as informações de tal maneira que os possíveis problemas apontados anteriormente ficassem minimizados. Foram utilizados dados correntes sobre o trabalho (ocupação atual), correlacionando-os com as informações correntes e cumulativas da fecundidade (TFT em 2000, história de nascimento e parturição). Foi assumido que a ocupação atual da mulher (sobretudo entre as mulheres de 30 a 34 anos, que já estão praticamente estabilizadas profissionalmente) é reflexo de sua trajetória ocupacional. Ou seja, mesmo que a ocupação de hoje não seja a mesma de quando a mulher começou a trabalhar e a ter filhos, pode representar a história ocupacional da mulher.

Apesar dessas justificativas, neste artigo, buscou-se identificar alguma associação temporal entre o comportamento reprodutivo e a ocupação da mulher para tornar as análises mais robustas. A Tabela 2 mostra a idade média de cada filho e o tempo médio no grupo ocupacional atual. Como o Censo Demográfico 2000 não possui dados sobre o tempo que o indivíduo está inserido na ocupação atual, foi utilizada a 
PNAD de 2002 como proxy, e então essa média foi comparada com a média da idade dos filhos da primeira até a quinta ordem de nascimento.

Como pode ser visto na Tabela 2, grande parte da parturição das mulheres alocadas nos grupos ocupacionais direção e gerência, nível superior, técnico-administrativo e rurais supostamente ocorreu concomitantemente ao exercício da ocupação atual. Nos demais grupos ocupacionais, há um maior descompasso temporal entre as idades médias dos filhos e o tempo médio na ocupação atual. Esse fato ocorre porque, nessas ocupações, a rotatividade é muito grande, não permitindo que as mulheres fiquem muito tempo no mesmo emprego; mesmo assim, é provável que essas mulheres estivessem executando atividades similares às observadas em 2000.

Tabela 2

Idade média dos filhos, segundo o grupo ocupacional das mães (30 a 34 anos) e o tempo médio das mulheres ( 30 a 34 anos) no grupo ocupacional

\begin{tabular}{l|c|c|c|c|c|c}
\hline Grupos ocupacionais & Filho 1 & Filho 2 & Filho 3 & Filho 4 & Filho 5 & TMO* \\
\hline Direção e gerência & 8,3 & 6,3 & 5,3 & 5,1 & 4,0 & 7,7 \\
Nível superior & 6,9 & 5,3 & 5,1 & 5,1 & 4,2 & 8,5 \\
Técnico-administrativo & 8,3 & 6,3 & 5,5 & 5,1 & 4,1 & 7,2 \\
Serviços & 10,4 & 7,9 & 6,6 & 5,7 & 4,4 & 5,0 \\
Rurais & 10,1 & 7,7 & 6,4 & 5,5 & 4,4 & 10,6 \\
Produção/manutenção & 11,1 & 8,8 & 7,2 & 6,0 & 4,5 & 5,8 \\
Empregadas domésticas & 11,0 & 8,6 & 6,9 & 5,7 & 4,4 & 4,6 \\
\hline
\end{tabular}

Fonte: IBGE, Censo Demográfico 2000; PNAD 2002.

* Tempo médio, em anos, no grupo ocupacional atual (PNAD 2002).

Em geral, os trabalhos sobre a mobilidade ocupacional no Brasil não utilizam a variável ocupação no nível de desagregação aplicado neste estudo. Na maioria das vezes, a mobilidade testada relaciona a passagem do status de carteira assinada para não assinada, formal para informal, empregada para desempregada e vice-versa (Oliveira, 2000). Essas análises não fornecem informações confiáveis que mostrem que a mobilidade ocupacional entre as mulheres ocorre dentro de um mesmo grupo ocupacional. Outros estudos trabalham na perspectiva de mobilidade de classe intergeracional (Scalon e Ribeiro, 2001; Pastore e Silva, 2000), uma perspectiva ainda mais distante do objeto deste artigo. 
Apesar dessa ausência de informações sobre a mobilidade ocupacional das mulheres (em nível de grupos ocupacionais), Elzira Oliveira (2000) afirma que é esperada pouca mobilidade ascendente entre as mulheres. Segundo essa autora, a trajetória ocupacional da mulher não sofre grandes transformações ao longo do tempo. Nesse sentido, se a mulher entra no mercado de trabalho em ocupações de baixo prestígio social, é esperado que ela permaneça nessas ocupações (se em 2000 a mulher estava em uma ocupação de baixo prestígio, é provável que estivesse em uma ocupação com as mesmas características em 1990, por exemplo). Ao mesmo tempo, se ela entra em uma posição de maior prestígio social, também é provável que continue. De acordo com Pastore e Silva (2000), observa-se uma grande imobilidade nessas ocupações.

Tais suposições permitem traçar um possível paralelo entre a história de nascimentos e a história ocupacional das mulheres - representada pela ocupação corrente, em virtude da esperada estabilidade das mulheres em seu grupo ocupacional.

\section{RESULTADOS}

Segundo a Tabela 3, entre as mulheres em ocupações de nível superior, quase $30 \%$ delas não possuem filhos. Por outro lado, entre as trabalhadoras rurais, apenas 4,2\% estão nessa situação. Ao mesmo tempo, nesse mesmo grupo de mulheres, mais de $35 \%$ possuem quatro filhos e mais, contra 2,2\% das mulheres em ocupações de nível superior.

De maneira geral, entre as mulheres com ocupações menos qualificadas (serviços, produção/manutenção, rurais e empregadas domésticas) e as não ocupadas, há uma parturição maior. Já nos grupos ocupacionais mais qualificados, existe uma grande concentração de mulheres com parturição de até dois filhos.

O Gráfico 1 mostra as TFTs de todos os grupos ocupacionais. Os valores encontrados reafirmam as diferenças observadas na distribuição percentual da parturição (Tabela 3). Entre os grupos ocupacionais mais qualificados, as TFTs encontradas são extremamente baixas, sobretudo entre as mulheres ocupadas nos setores de nível superior. Por outro lado, entre as mulheres nas ocupações menos qualificadas do mercado de trabalho brasileiro (trabalho rural e doméstico) e entre as mulheres não ocupadas, são encontradas as maiores TFTs, com destaque para as trabalhadoras rurais, que têm, em média, 3,24 filhos. Já as mulheres 
Diferenciais no Comportamento Reprodutivo das Mulheres Brasileiras...

Tabela 3

Distribuição percentual das mulheres de 30 a 34 anos, segundo a parturição e o grupo ocupacional

Brasil (2000)

\begin{tabular}{l|c|c|c|c|c|c|c}
\hline \multirow{2}{*}{ Grupo ocupacional } & \multicolumn{7}{|c}{ Número de filhos nascidos vivos } \\
\cline { 2 - 8 } & $\mathbf{0}$ & $\mathbf{1}$ & $\mathbf{2}$ & $\mathbf{3}$ & $\mathbf{4}$ & $\mathbf{5 +}$ & Total \\
\hline Direção e gerência & 22,2 & 30,5 & 33,6 & 11,4 & 1,7 & 0,6 & 100,0 \\
Nível superior & 29,6 & 32,9 & 28,1 & 7,2 & 1,5 & 0,7 & 100,0 \\
Técnico-administrativo & 18,9 & 32,7 & 33,3 & 11,6 & 2,5 & 1,0 & 100,0 \\
Serviços & 9,6 & 22,8 & 34,9 & 19,9 & 7,5 & 5,4 & 100,0 \\
Produção/manutenção & 10,4 & 26,3 & 34,6 & 18,3 & 6,2 & 4,1 & 100,0 \\
Rurais & 4,2 & 12,0 & 25,8 & 22,7 & 13,8 & 21,6 & 100,0 \\
Empregadas domésticas & 7,0 & 19,4 & 31,0 & 23,5 & 10,7 & 8,4 & 100,0 \\
Não ocupadas & 4,9 & 17,5 & 34,7 & 22,5 & 9,9 & 10,5 & 100,0 \\
\hline Total & $\mathbf{9 , 6}$ & $\mathbf{2 1 , 8}$ & $\mathbf{3 3 , 4}$ & $\mathbf{1 9 , 5}$ & $\mathbf{8 , 0}$ & $\mathbf{7 , 7}$ & $\mathbf{1 0 0 , 0}$ \\
\hline
\end{tabular}

Fonte: IBGE, Censo Demográfico 2000.

\section{Gráfico 1}

Taxa de fecundidade total das mulheres de 30 a 34 anos, segundo o grupo ocupacional

Brasil (2000)*

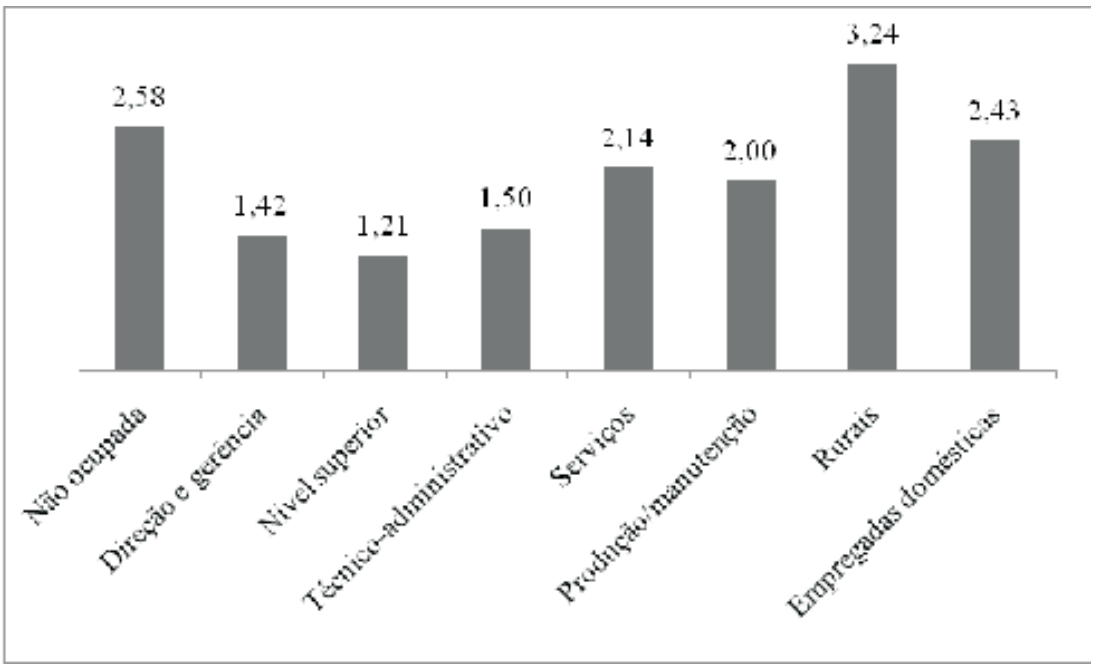

Fonte: IBGE, Censo Demográfico 2000.

* A TFT foi calculada a partir da técnica de PPR (Parity Progression Ratio). 
dos setores de serviços, produção e manutenção apresentaram uma TFT em torno do nível de reposição (2,1 filhos por mulher) ${ }^{10}$.

De maneira geral, são identificados três padrões de TFT, segundo o grupo ocupacional da mulher: TFT muito abaixo do nível de reposição para mulheres em ocupações mais qualificadas; TFT ao nível de reposição para mulheres em ocupações intermediárias (serviços e produção/manutenção); e TFT acima do nível de reposição para as mulheres alocadas em ocupações manuais, de baixo prestígio social e entre as mulheres não ocupadas.

De acordo com a Tabela 4, existem diferenças importantes nas médias de idade ao ter os filhos segundo o grupo ocupacional da mulher. Essas diferenças são mais significativas em relação aos filhos de ordem 1 e 2 . A partir do quarto filho, as diferenças se reduzem bastante; e a partir do quinto já não se observam grandes variações nas médias de idade. Entre as mulheres de nível superior, por exemplo, a idade média ao ter o primeiro filho é 25,2 anos, ao passo que para as mulheres não ocupadas a idade média ao ter o primeiro filho é 18,8 anos. Se as mulheres de nível superior levam quase onze anos, em média, para ter o primeiro filho, dado o ponto inicial de 15 anos, as mulheres não ocupadas levam, em média, apenas 3,8 anos.

A Tabela 5 separa as mulheres segundo o grupo ocupacional e a parturição total. Entre as mulheres com parturição 1, a ocupação parece ser

Tabela 4

Idade média ao ter os filhos, segundo a ordem de nascimento e o grupo ocupacional da mulher

Brasil (2000)

\begin{tabular}{l|c|c|c|c|c}
\hline \multirow{2}{*}{ Grupo ocupacional } & \multicolumn{5}{|c}{ Ordem de nascimento } \\
\cline { 2 - 6 } & $\mathbf{1}$ & $\mathbf{2}$ & $\mathbf{3}$ & $\mathbf{4}$ & $\mathbf{5}$ \\
\hline Direção e gerência & 23,8 & 26,0 & 27,0 & 27,2 & 28,3 \\
Nível superior & 25,2 & 27,0 & 27,3 & 27,3 & 28,2 \\
Técnico-administrativo & 23,8 & 25,9 & 26,7 & 27,2 & 28,2 \\
Serviços & 21,7 & 24,2 & 25,5 & 26,6 & 27,9 \\
Produção/manutenção & 21,9 & 24,4 & 25,8 & 26,7 & 27,9 \\
Rurais & 20,9 & 23,3 & 24,9 & 26,2 & 27,7 \\
Empregadas domésticas & 21,0 & 23,5 & 25,2 & 26,5 & 27,9 \\
Não ocupadas & 18,8 & 20,9 & 23,2 & 25,5 & 28,0 \\
\hline
\end{tabular}

Fonte: IBGE, Censo Demográfico 2000. 
um componente importante na escolha do momento de ter o filho. Para as mulheres com ocupação de nível superior, a média de idade ao ter o filho é 27,4 anos, ao passo que, entre as mulheres empregadas domésticas, a idade média ao ter o filho é 24,5 anos. Uma diferença de 2,9 anos. Como foi demonstrado anteriormente, na Tabela 4, sem a separação por parturição, essa diferença é de 4,2 anos. Entre as mulheres com parturição 2, ainda se observam diferenças importantes na idade média ao ter os filhos, mas, à medida que se aumenta a parturição, a possível influência da ocupação vai diminuindo, até desaparecer. Para as mulheres de parturição 4 e 5, por exemplo, o fato de estarem em um determinado tipo de ocupação parece não influenciar na média de idade ao ter os filhos, uma vez que os resultados encontrados mostram um mesmo padrão reprodutivo entre essas mulheres, independentemente da ocupação. Apesar disso, apenas uma parcela ínfima das mulheres mais qualificadas profissionalmente terão muitos filhos. Outro aspecto importante na Tabela 5 é o fato de as mulheres não ocupadas, com até dois filhos, terem uma média de idade maior que as mulheres dos grupos ocupacionais menos qualificados (serviços, produção/manutenção, rural e empregadas domésticas) no momento da ocorrência dos nascimentos.

Os intervalos entre os nascimentos, como era esperado, acompanham o padrão observado na Tabela 5. De acordo com a Tabela 6, apenas para as mulheres com um e dois filhos se observam diferenças nos intervalos intergenésicos ao se comparar os grupos ocupacionais. Para as mulheres com parturição 4 e 5, principalmente, os intervalos entre os nascimentos são praticamente os mesmos, independentemente da ocupação.

\section{PROVÁVEIS EXPLICAÇÕES PARA OS DIFERENCIAIS NO COMPORTAMENTO REPRODUTIVO ENTRE OS GRUPOS OCUPACIONAIS}

De acordo com os resultados deste estudo, existe uma diferença no regime reprodutivo dos grupos ocupacionais, mas não se pode afirmar categoricamente que determinada característica de um grupo ocupacional seja responsável pelo comportamento reprodutivo das mulheres desse grupo. O que se pode fazer são suposições sobre a relação entre ocupação e fecundidade. Além disso, é importante deixar claro que os resultados, por seu caráter descritivo, podem mascarar possíveis relações entre o comportamento reprodutivo e outras variáveis. 


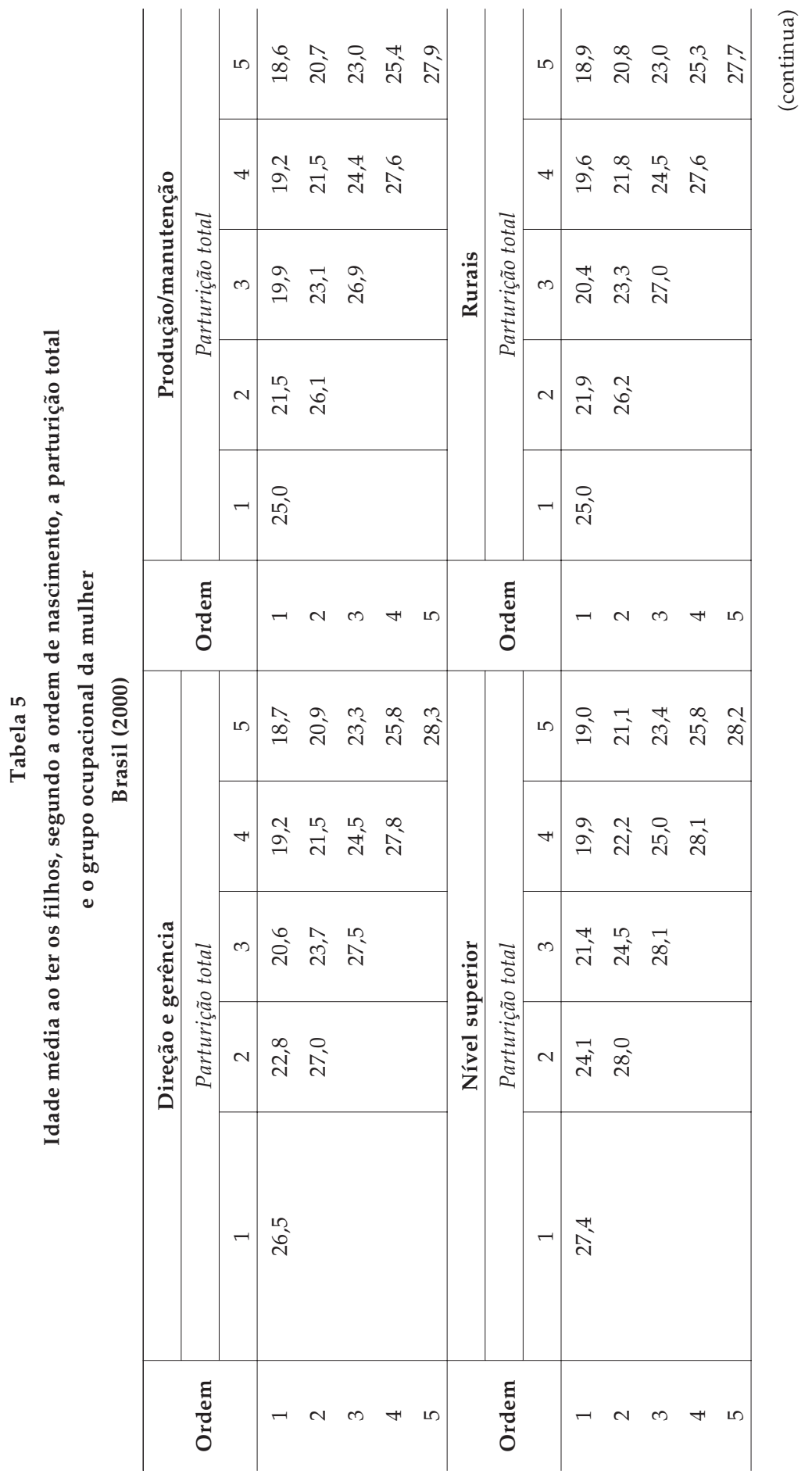


Diferenciais no Comportamento Reprodutivo das Mulheres Brasileiras...

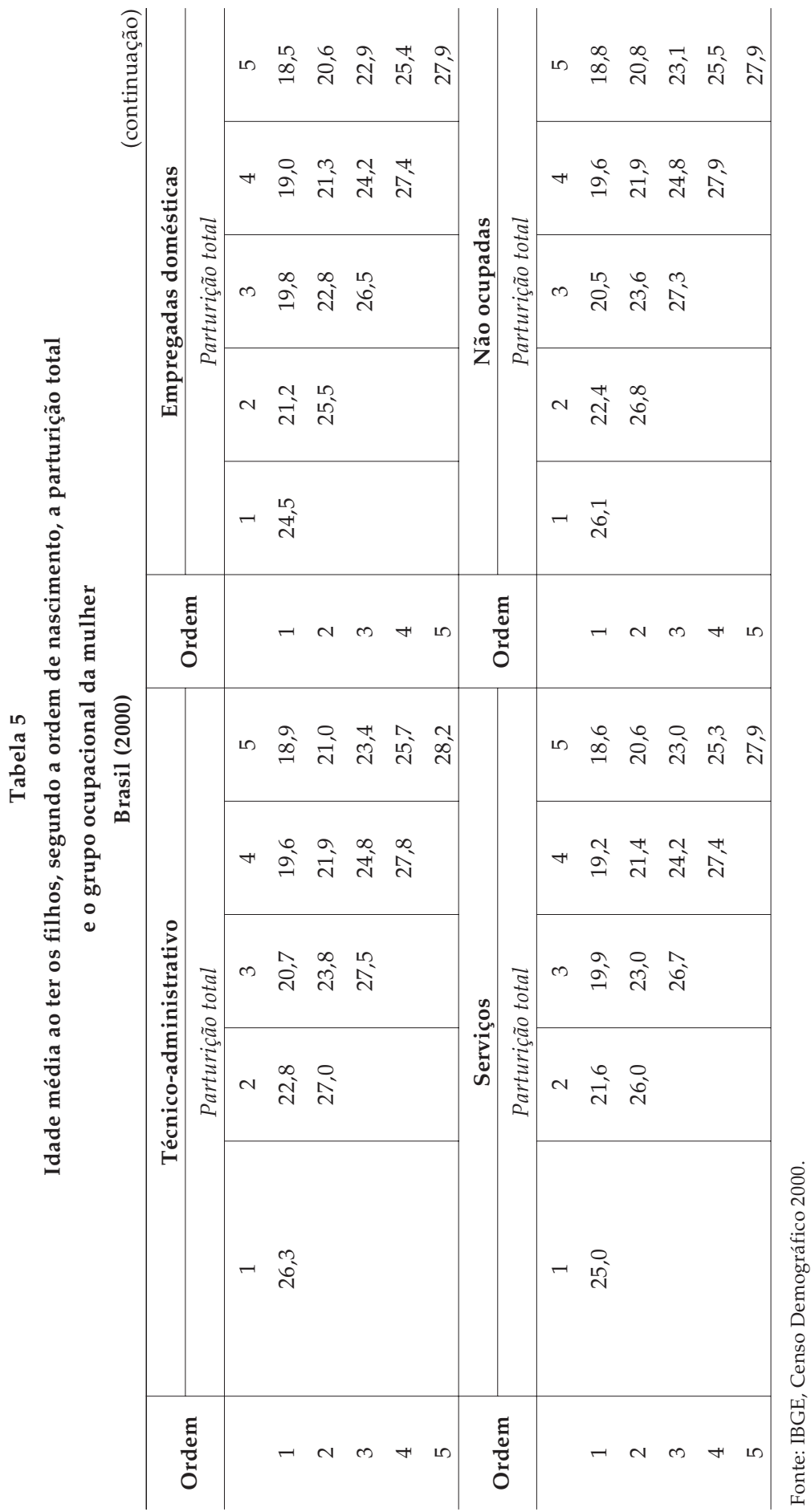


Cláudio Santiago Dias Júnior

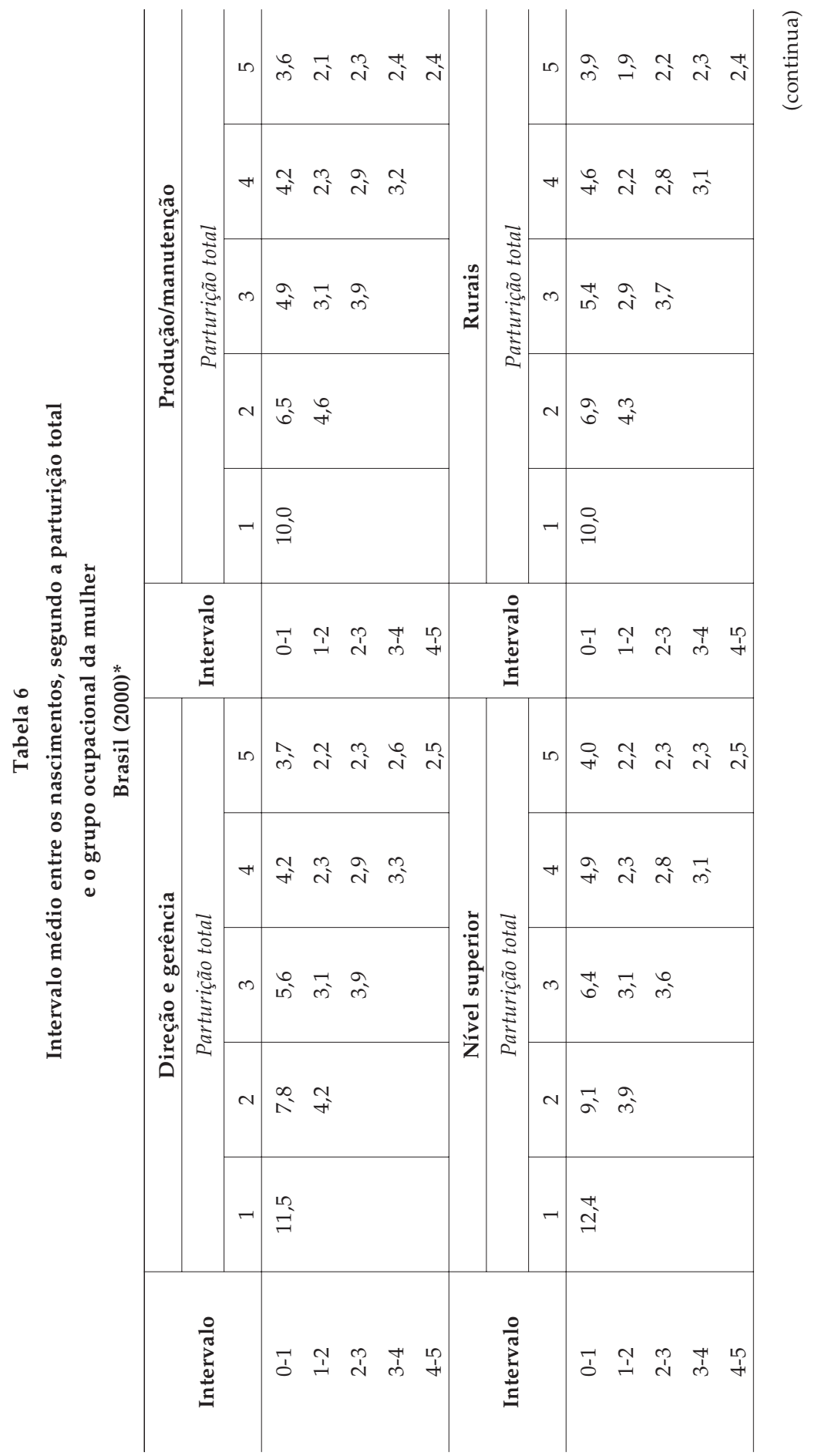


Diferenciais no Comportamento Reprodutivo das Mulheres Brasileiras...

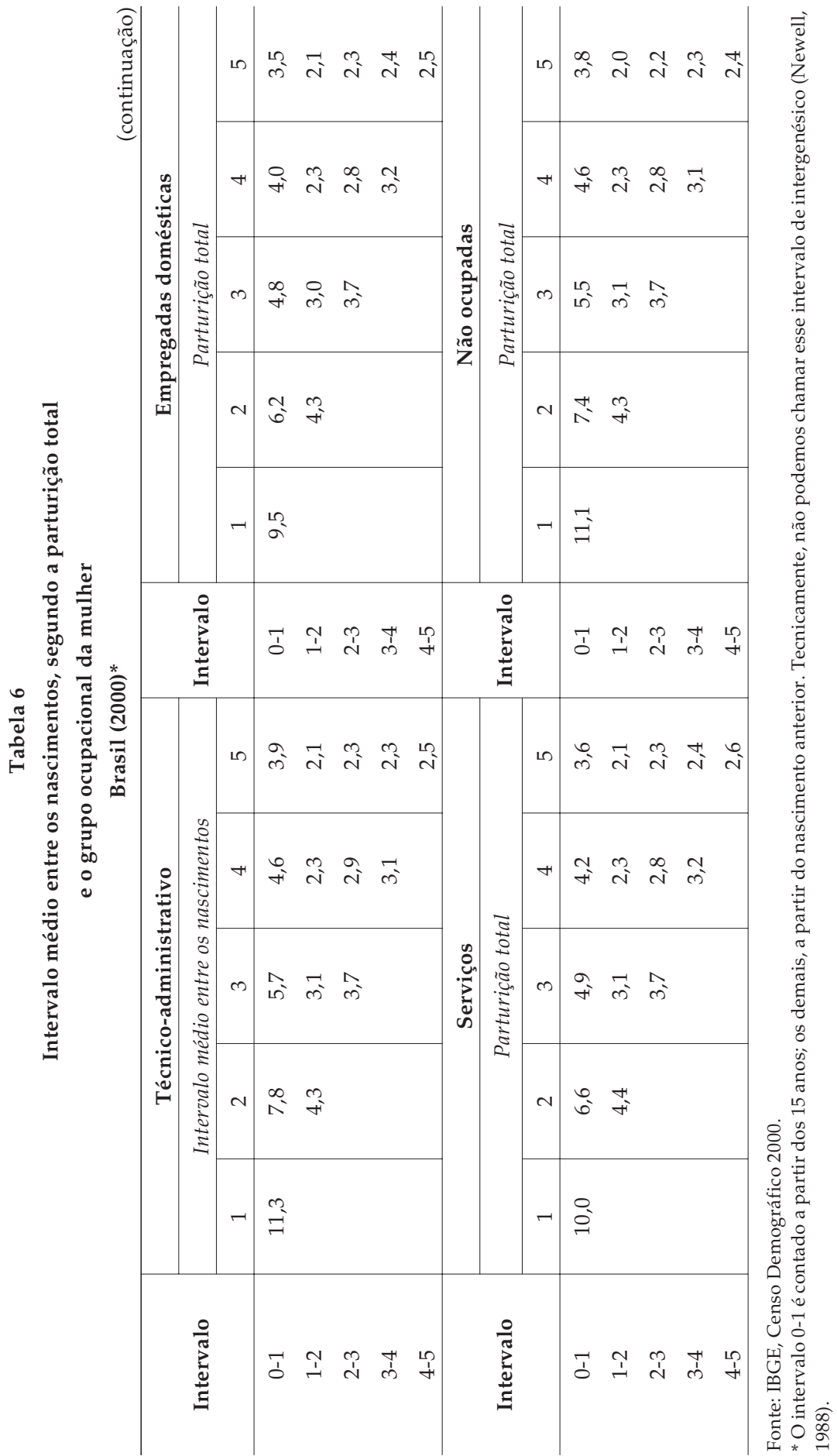


Nos grupos ocupacionais mais qualificados (direção e gerência, nível superior e nível técnico-administrativo), o grau de formalização das relações de trabalho é maior (Dias Júnior, 2007). Essa característica é apontada pela literatura corrente como possível fator explicativo para a baixa fecundidade, uma vez que o grau de formalização das atividades laborativas, cuja exigência maior é o cumprimento de horários, pode aumentar a incompatibilidade entre a participação no mercado de trabalho e a maternidade (Degraff e Anker, 2004). Ao mesmo tempo, a alta qualificação, reflexo da alta escolaridade, aumenta os custos de oportunidade de ter filhos dessas mulheres. Esse aumento dos custos de oportunidade pode fazer com que as mulheres passem a controlar mais efetivamente a maternidade, com o adiamento do primeiro filho e/ou a redução da parturição, mantendo-se atraentes para o mercado de trabalho (McDonald, 2001; Hoem e Hoem, 1989; Becker, 1981). Nas ocupações de maior status social, encontram-se as mulheres que, em média, retardam por mais tempo a maternidade e controlam a progressão da parturição (Hewllet, 2002). É plausível supor que a preparação para ingressar nesses tipos de ocupação (via escolaridade) gera a postergação e que as características dessas ocupações e os desafios do mercado de trabalho geram o controle da parturição.

Entre os grupos ocupacionais menos qualificados (serviços, rurais, produção/manutenção e empregadas domésticas), existe um contingente maior de mulheres com poucos anos de estudo e com uma relação mais informal de trabalho (Dias Júnior, 2007). Essas duas características podem ser a pista para entender o regime reprodutivo desses grupos ocupacionais (idade mais baixa ao ter o primeiro filho e maior parturição/fecundidade quando comparados com os grupos ocupacionais mais qualificados). A pouca escolaridade remete, quase invariavelmente, aos piores trabalhos. Esses trabalhos normalmente remuneram mal e tendem a não ter um contrato formal. Não há, por parte das trabalhadoras, grandes incentivos nem motivos para investir em suas carreiras profissionais. $\mathrm{O}$ fato de estarem, na maioria das vezes, sob um contrato informal, facilita a entrada e a saída do mercado de trabalho. Esse fenômeno reduz significativamente a incompatibilidade entre as obrigações maternas e o trabalho. Quando necessário, a mulher se afasta do trabalho e retorna quando lhe convém, sem grandes perdas salariais (dado que o salário tende a ser mais baixo, em relação ao trabalho formal, e guarda pouca relação com a experiência) e sem perdas do saber necessário para reingressar na profissão. Nesse 
ambiente desfavorável, ter ou não filhos pode não ser uma grande questão, visto que o custo de oportunidade é baixo (England, 1991).

Conclui-se que o tipo de trabalho que a mulher realiza pode estar associado a seu comportamento reprodutivo (Nações Unidas, 1985), influenciando na idade ao ter os filhos (Hoem e Hoem, 1989), nos riscos de progressão da parturição (Kalwij, 2000) e na parturição final (Hewllet, 2002). Certamente, a discussão da relação entre o comportamento reprodutivo e o trabalho da mulher pode lançar luz sobre mais um dos aspectos que explicam o declínio acentuado das TFTs no Brasil. É possível que as exigências do mercado de trabalho (Hewllet, 2002), a ausência de uma assistência social eficiente à mãe trabalhadora (Favaro, 2004; Presser, 1989) e a dificuldade de dividir equitativamente os trabalhos domésticos com o parceiro (Bruschini, 2006) possam responder por boa parte da fecundidade abaixo do nível de reposição da população no Brasil. Nesse sentido, este estudo pode colaborar com essa discussão, uma vez que demonstra a importância da ocupação da mulher na composição do regime reprodutivo.

(Recebido para publicação em setembro de 2007)

(Reapresentado em fevereiro de 2009) (Aprovado para publicação em julho de 2009) 


\section{Cláudio Santiago Dias Júnior}

\section{NOTAS}

1. Segundo o Ministério do Trabalho e Emprego (MTE), a nova CBO procurou, ao mesmo tempo, maximizar as características e as competências dos grupos ocupacionais e minimizar a influência da educação na caracterização desses grupos.

2. O termo tempo da fecundidade, utilizado em nosso trabalho, não representa o impacto do espaçamento decorrente da mudança na idade das progressões por parturição, como define Rios-Neto (2005). Refere-se simplesmente ao momento da ocorrência do nascimento.

3. A exclusão das mulheres que tiveram o primeiro filho com menos de 15 anos evita a presença de informações que possam distorcer nossos dados. Tomamos o exemplo de uma mulher com 30 anos que se casou com um homem de 50; este tem seu filho de 18 anos morando com a família. Nesse caso, para nossa pesquisa, essa mulher teria tido esse filho aos 12 anos (quando, na verdade, ele é seu enteado). Caso ela tenha um filho próprio de 2 anos, o intervalo intergenésico do primeiro para o segundo filho dessa mulher seria de 16 anos. Se acumulássemos muitos casos dessa natureza, nossos resultados estariam equivocados. Evidentemente, nosso procedimento não impede que haja outros casos de enteados que consideramos serem filhos, pois a diferença de idade em relação à mulher é maior ou igual a 15 anos.

4. De maneira geral, as mulheres com informações completas são brancas, mais jovens, possuem um nível mais alto de escolaridade, de renda e de ocupação, têm menos filhos e residem nas regiões Sul-Sudeste. Já as mulheres com informações incompletas são predominantemente negras, mais velhas, possuem um nível mais baixo de educação, de renda e de ocupação, têm mais filhos e residem nas regiões Norte-Nordeste.

5. É provável que as diferenças socioeconômicas ajudem a explicar a ausência dos filhos no caso das mulheres de família incompleta. Como essas mulheres apresentam uma situação econômica mais desfavorável, podemos esperar que, nesse grupo, as taxas de mortalidade dos filhos sejam maiores e que a mobilidade dos filhos na busca de oportunidades de emprego seja mais intensa.

6. A descrição completa dessa categorização pode ser encontrada em http://www. mtecbo.gov.br.

7. Segundo Dias Júnior (2007), nos grupos mais qualificados (direção e gerência, nível superior e técnico-administrativo), a estrutura etária é mais envelhecida, com uma baixa proporção de negras. Em média, as trabalhadoras nesses grupos possuem alto grau de escolaridade e de formalização das relações de trabalho. Entre os grupos ocupacionais menos qualificados, observa-se uma estrutura etária mais jovem, escolaridade e renda menores, uma jornada de trabalho, em média, maior do que a jornada de trabalho das ocupações mais qualificadas e baixo grau de formalização das relações de trabalho. Além disso, esses grupos possuem um grande percentual de mulheres negras.

8. Destacamos que os dados longitudinais não resolvem totalmente a questão da causalidade, pois os eventos podem não seguir a ordem inicial das escolhas definidas pela mulher. Pode ocorrer um nascimento inesperado e/ou um nascimento múltiplo, fazendo com que a mulher redefina suas estratégias profissionais (por exemplo, o adiamento de um curso de especialização, a saída do mercado de trabalho, a redução da jornada de trabalho, entre outras escolhas). Da mesma maneira, uma promoção ines- 
perada no serviço, bem como a possibilidade de se aperfeiçoar profissionalmente, pode fazer com que a mulher adie a maternidade. Ou seja, esses eventos podem influenciar a ordem das escolhas previstas pelas mulheres.

9. De acordo com Pazello (2004), a utilização de variáveis instrumentais para o estudo da fecundidade e do mercado de trabalho é complicada, uma vez que não temos variáveis que se correlacionam apenas com a fecundidade, e não com a participação da mulher no mercado de trabalho.

10. O nível de reposição é o nível de fecundidade no qual uma coorte de mulheres tem o número de filhos suficiente para recompor a si mesma na população. Normalmente esse valor é de 2,1 filhos por mulher.

\section{REFERÊNCIAS BIBLIOGRÁFICAS}

ALVES, José Eustáquio Diniz. (2004), “Questões Demográficas: Fecundidade e Gênero”. Texto para Discussão, no 9, Ence/IBGE.

ANKER, Richard. (1997), "Theories of Occupational Segregation by Sex: An Overview". International Labour Review, vol. 136, no 3, pp. 315-339.

BECKER, Gary S. (1981), A Treatise on the Family. Cambridge, Harvard University Press.

BERQUÓ, Elza. (1980), “Análise do Ciclo Vital Visto da Perspectiva do 'Quantum' e do 'Tempo' da Fecundidade: Estudo Comparativo de Contextos Brasileiros", in Anais do Encontro Nacional de Estudos Populacionais. São Paulo, Abep, vol. 2, pp. 689-708.

___ e CAVENAGHI, Suzana M. (2005), “Brazilian Fertility Regimes: Profiles of Women Below and Above Replacement Levels", in XXV International Population Conference IUSSP. Tours, IUSSP, vol. 1, pp. 1-13.

BLAU, David M. e ROBINS, Philip K. (1989), “Fertility, Employment, and Child-Care Costs". Demography, vol. 26, no 2, pp. 287-299.

BLAU, Francine D., FERBER, Marianne A. e WINKLER, Anne E. (1998), The Economics of Women, Men, and Work. Upper Saddle River, NJ, Prentice Hall.

BONGAARTS, John e FEENEY, Griffith. (1998), "On the Quantum and Tempo of Fertility". Population and Development Review, vol. 24, no 2, pp. 271-291.

BREWSTER, Karin L. e RINDFUSS, Ronald R. (2000), “Fertility and Women's Employment in Industrialized Nation". Annual Review of Sociology, vol. 26, pp. 271-296.

BRUSCHINI, Cristina. (2006), “Trabalho Doméstico: Inatividade Econômica ou Trabalho Não Remunerado?". Revista Brasileira de Estudos da População, vol. 23, no 2, pp. 331-353.

CHEN, Gongyue e ASTEBRO, Thomas B. (2003), "How to Deal with Missing Categorical Data: Test of a Simple Bayesian Method". Organizational Research Methods, vol. 6, no3, pp. 309-327. 


\section{Cláudio Santiago Dias Júnior}

CRAMER, James C. (1980), "Fertility and Female Employment: Problems of Causal Direction". American Sociological Review, vol. 45, pp. 167-190.

DEGRAFF, Debora S. e ANKER, Richard. (2004), “Gênero, Mercados de Trabalho e o Trabalho das Mulheres", in A. Pinnelli (org.), Gênero nos Estudos de População. Campinas, Abep, pp. 163-197.

DIAS JÚNIOR, Cláudio Santiago. (2007), Comportamento Reprodutivo: Uma Análise a Partir do Grupo Ocupacional das Mulheres. Tese de doutorado, Centro de Desenvolvimento e Planejamento Regional, Universidade Federal de Minas Gerais, Belo Horizonte.

ELLINGSAETER, Anne L. e RONSEN, Marit. (1996), “The Dual Strategy: Motherhood and the Work Contract in Scandinavian". European Journal of Population, vol. 12, no 3, pp. 239-260.

ENGELHARDT, Henriette, KÖGEL, Tomas e PRSKAWETZ, Alexia. (2004), "Fertility and Women's Employment Reconsidered: A Macro-Level Time-Series Analysis for Developed Countries, 1960-2000". Population Studies, vol. 58, no 1, pp. 109-120.

ENGLAND, Paula. (1991), Comparative Worth: Theories and Evidence. New York, Aldine de Gruyter.

FAVARO, Donata. (2004), Women's Employment around Childbirth. Trabalho apresentado no XIX Convegno Annuale di Economia del Lavoro, Modena, 23-24 de setembro.

FONG, Monica S. (1976), "Female Labor Force Participation and Fertility: Some Methodological and Theoretical Considerations". Social Biology, vol. 23, no 1, pp. 45-54.

FUNDAÇÃOSEADE (Fundação Sistema Estadual de Análise de Dados). (2004), “Natalidade e Fecundidade em São Paulo: O Risco da Interpretação Equivocada dos Dados". SP Demográfico, vol. 5, no 12.

HAKIM, Catherine. (1992), "Explaining Trends in Occupational Segregation: The Measurement, Causes, and Consequences of the Sexual Division of Labour". European Sociological Review, vol. 8, no 2, pp. 127-152.

HEWLLET, Sylvia A. (2002), Creating a Life: Professional Women and the Quest for Children. New York, Miramax Books.

HIRATA, Helena e KERGOAT, Daniele. (2003), “A Divisão Sexual do Trabalho Revisitada", in M. Maruani e H. Hirata (orgs.), As Novas Fronteiras da Desigualdade: Homens e Mulheres no Mercado de Trabalho. São Paulo, Senac, pp. 111-123.

HOEM, Britta e HOEM, Janm. (1989), “The Impact of Women's Employment on Second and Third Births in Sweden". Population Studies, vol. 43, no 1, pp. 47-67.

HORTA, Cláudia Júlia, CARVALHO, José Alberto Magno de e NOGUEIRA, Olinto José Oliveira. (2005), "Evolução do Comportamento Reprodutivo da Mulher Brasileira 1991-2000. Cálculo da Taxa de Fecundidade Total em Nível Municipal". Revista Brasileira de Estudos de População, vol. 22, no 1, pp. 131-140.

IBGE (Instituto Brasileiro de Geografia e Estatística). (2000), Nupcialidade e Fecundidade: Resultados da Amostra. Rio de Janeiro, IBGE. 
JONES, Elise F. (1981), “The Impact of Women's Employment on Marital Fertility in the U.S, 1970-1975". Population Studies, vol. 35, no 2, pp. 161-173.

KALWIJ, Adriaan S. (2000), "The Effects of Female Employment Status on the Presence and Number of Children". Journal of Population Economics, vol. 13, no2, pp. 221-239.

KÖGEL, Tomas. (2004), “Did the Association between Fertility and Female Employment within OECD Countries Really Change Its Sign?". Journal of Population Economics, vol. 17, no 1 , pp. 45-65.

LAM, David e DURYEA, Suzanne. (1999), "Effects of Schooling on Fertility, Labor Supply, and Investment in Children with Evidence from Brazil". Journal of Human Resources, vol. 34, no 1, pp. 160-192.

LLOYD, Cynthia B. (1990), Understanding the Relationship between Women's Work and Fertility: The Contribution of the World Fertility Surveys. New York, Population Council (Working Paper, no 9).

MCDONALD, Peter. (2001), Theory Pertaining to Low Fertility. Trabalho apresentado no International Perspectives on Low Fertility: Trends, Theories and Policies. IUSSP, Tóquio, 21-23 de março.

MIRANDA-RIBEIRO, Adriana. (2004), “O Efeito Tempo e as Tendências da Fecundidade Brasileira: Uma Aplicação do Modelo de Bongaarts e Feeney". Anais do XIV Encontro Nacional de Estudos Populacionais, Campinas, Abep.

NAÇÕES UNIDAS. (1985), Women's Employment and Fertility: A Comparative Analysis of World Fertility Survey Results for 38 Developing Countries. New York (Population Studies, no 96).

NEWELL, Colin. (1988), Methods and Models in Demography. New York, The Guilford Press.

OLIVEIRA, Elzira Lucia de. (2000), “Padrão de Mobilidade de Ciclo de Vida Feminino no Mercado de Trabalho". Anais do XII Encontro Nacional de Estudos Populacionais. Brasil 500 Anos: Mudanças e Continuidades. Caderno de Resumos. Belo Horizonte, vol. 1.

ONDRICH, Jan e SPIESS, C. Katharina. (1998), "Care of Children in a Low Fertility Setting: Transition between Home and Market Care for Pre-School Children in Germany". Population Studies, vol. 52, no 1, pp. 35-48.

PASTORE, José e SILVA, Nelson do Valle. (2000), Mobilidade Social no Brasil. São Paulo, Makron Books.

PAZELLO, Elaine Toldo. (2004), A Maternidade e a Mulher no Mercado de Trabalho. Tese de doutorado em Economia, Faculdade de Economia, Administração e Contabilidade, Universidade de São Paulo, São Paulo.

PRESSER, Harriet B. (1989), “Can We Make Time for Children? The Economy, Work Schedule, and Child Care”. Demography, no 26, pp. 523-543.

PRESTON, Samuel H., HEUVELINE, Patrick e GUILLOT, Michel. (2001), Demography: Measuring and Modeling Population Processes. Malden, Blackwell.

RIOS-NETO, Eduardo L. G. (2005), "Questões Emergentes na Demografia Brasileira”. Texto para Discussão, no 276, Cedeplar/UFMG. 


\section{Cláudio Santiago Dias Júnior}

RYDER, Norman B. (1969), "The Emergence of a Modern Fertility Pattern: United States, 1917-1966", in S. J. Behrman, L. Corsa Jr. e R. Freedman (eds.). Fertility and Family Planning: A World View. Ann Arbor, University of Michigan, pp. 99-123.

SAUVY, Alfred. (1979), Elementos de Demografia. Rio de Janeiro, Zahar.

SCALON, Maria Celi e RIBEIRO, Carlos Antônio Costa. (2001), “Mobilidade de Classe no Brasil em Perspectiva Comparada". DADOS, vol. 44, no 1, pp. 53-96.

SCHAFER, Joe. (1999), "Multiple Imputation: A Primer". Statistical Methods in Medical Research, no 8, pp. 3-15.

SCHOEN, Robert. (2006), “Insights from Parity Status Life Tables for the 20th Century U.S". Social Science Research, vol. 35, no 1, pp. 29-39.

STOLZENBERG, Ross M. e WAITE, Linda J. (1977), "Age and the Relationships between Young Women's Plans for Childbearing and Employment". American Sociological Review, vol. 42, pp. 769-783.

VERONA, Ana Paula de Andrade. (2004), A Relação entre Fecundidade e Educação dos Filhos: Um Experimento Natural Utilizando Dados de Gêmeos. Dissertação de mestrado, Centro de Desenvolvimento e Planejamento Regional, Universidade Federal de Minas Gerais, Belo Horizonte.

VILLARREAL, Marcela. (1996), “Women's Economic Activities and Fertility: Overview of the Interactions and Policy Implications". Population and Women. New York, United Nations, pp. 301-311.

WOOD, Charles H. e CARVALHO, José Alberto Magno. (1994), A Demografia da Desigualdade no Brasil. Rio de Janeiro, Ipea. 


\section{ABSTRACT \\ Differences in Reproductive Behavior among Brazilian Women: An Analysis Based on Occupational Groups}

The aim of this study was to analyze reproductive behavior based on women's occupation in the work market. The hypothesis is that given occupations are associated with different strategies by women in relation to fertility, resulting in different reproductive histories. The study used the database from the Population Census for 2000 conducted by the Brazilian Institute of Geography and Statistics (IBGE). Women's birth histories were reconstructed, and demographic tools were used to perform a descriptive analysis of the relationship between women's reproductive behavior and their occupation. According to the findings, women in more highly qualified occupational groups tended to have fewer children and postpone motherhood longer.

Key words: reproductive behavior; occupation; birth history

\section{RÉSUMÉ}

Différences de Comportement Reproductif chez les Femmes Brésiliennes: Une Analyse à partir des Groupes Professionnels

Dans cette étude, on cherche à examiner le comportement reproductif à partir de la profession des femmes sur le marché du travail. On part de l'hypothèse que certaines professions sont associées aux différentes stratégies utilisées par les femmes quant à la fécondité, dont résultent des régimes reproductifs différents. On a utilisé les données du recensement brésilien de l'Institut Brésilien de Géographie et de Statistique (IBGE) en 2000. On a reconstitué l'histoire des naissances de ces femmes et, par le moyen d'instruments démographiques, on a effectué une analyse du rapport entre leur comportement reproductif et leurs emplois. On a vérifié que les groupes professionnels les plus qualifiés sont ceux où les femmes ont le moins d'enfants et retardent le plus la maternité.

Mots-clé: comportement reproductif; profession; histoire des naissances 